\title{
An Empirical Model of Growth Through Product Innovation
}

\author{
Rasmus Lentz \\ Boston University
}

\author{
Dale T. Mortensen \\ Northwestern University
}

January 14, 2005

\begin{abstract}
Productivity dispersion across firms is large and persistent, and worker reallocation among firms is an important source of productivity growth. The purpose of the paper is to estimate the structure of an equilibrium model of growth through innovation. The model is a modified version of the Schumpeterian theory of firm evolution and growth developed by Klette and Kortum (2002). The data set is a panel of Danish firms than includes information on value added, employment, and wages. The model's fit is good and the structural parameter estimates have interesting implications for the aggregate growth rate and the contribution of worker reallocation to it.
\end{abstract}




\section{Introduction}

In their review article, Bertelsman and Doms (2000) draw three lessons from empirical productivity studies based on longitudinal plant and firm data: First, the extent of dispersion in productivity across production units, firms or establishments, is large. Second, productivity rank of any unit in the distribution is highly persistent. Third, a large fraction of aggregate productivity growth is the consequence of worker reallocation.

Although the explanations for productive firm heterogeneity are not fully understood, economic principles suggest that its presence should induce worker reallocation from less to more productive firms as well as from exiting to entering firms. There is ample evidence that workers do flows from one firm to another frequently. As Davis, Haltiwanger and Shuh (1996) and others document, job and worker flows are large, persistent, and essentially idiosyncratic in the U.S. Recently, Fallick and Fleischman (2001) and Stewart (2002) find that job to job flows without a spell of unemployment in the U.S. represent at least half of the separations and is growing. In their analysis of Danish matched employer-employee IDA data, Frederiksen and Westergaard-Nelsen (2002) report that the average establishment separation rate over the 1980-95 period was $26 \%$. About two thirds of the outflow represents the movement of workers from one firm to another.

In a companion paper, Lentz and Mortensen (2004), we develop a stochastic general equilibrium model in which more profitable firm's grow faster and contribute more to the aggregate growth rate through product innovation. The model is a variation on that proposed by Klette and Kortum (2004), which itself builds on the endogenous growth model of Grossman and Helpman (1991). By design, their model is consistent with stylized facts about product innovation and its relationship to the dynamics of firm size evolution. We adopt the approach because it provides an explanation for the fact that there is no correlation between labor force size and labor productivity but a strong positive association between value added and labor productivity in Danish firm data. Furthermore, the model provides a direct link between worker reallocation and productivity growth.

The purpose of this paper is to fit our version of the model to Danish firm data. Given the parameter estimates obtained, we explore the model's quantitative implications for the sources of aggregate productivity growth and the relationship between the equilibrium and socially optimal rates of growth. We find that the reallocation of workers from less to more productive 
surviving firms accounts for over $44 \%$ of productivity growth. We also show that the equilibrium rate of growth implied by the model is substantially less than that which is socially optimal. In the solution to the planner's problem, firms that can develop more profitable products invest more in R\&D than they do in equilibrium. As a consequence, reallocation among surviving firms accounts for a larger share, $66 \%$, of a larger growth rate.

In the model, firms are monopoly suppliers of differentiated intermediate products that serve as inputs in the production of a final consumption good. Better quality products are introduced from time to time as the outcome of R\&D investment by both existing firms and new entrants. As new products displace old, the process of creative destruction induces the need to reallocate workers across productive activities. In the version of the model estimated here, product quality differs across firms. In our earlier paper, we established the existence of a general equilibrium solution to the model. In this one, we use the equilibrium relationships implied by the model and information drawn from a Danish panel of firms to estimate the model's parameters.

\section{Danish Firm Data}

Danish firm data provide information on productivity dispersion and the relationships among productivity, employment, and sales. The available data set is an annual panel of privately owned firms for the years 1992-1997 drawn from the Danish Business Statistics Register. The sample of approximately 6,700 firms is restricted to those with 20 or more employees. The variables observed in each year include value added $(Y)$, the total wage bill $(W)$, and full-time equivalent employment $(N)$. In this paper we use these relationships to motivate the theoretical model studied. Both $Y$ and $W$ are measured in Danish Kroner while $N$ is a body count.

Non-parametric estimates of the distributions of two alternative measures of a firm's labor productivity are illustrated in Figure 1. The first measure of firm productivity is value added per worker $(Y / N)$ while the second is valued added per unit of quality adjusted employment $\left(Y / N^{*}\right)$. Standard labor productivity misrepresents cross firm productivity differences to the extent that labor quality differs across firms. However, if more productive workers are compensated with higher pay, as would be true in a competitive labor market, one can use a wage weighted index of employment to correct for this source of cross firm differences in productive efficiency. Formally, the 
constructed quality adjusted employment of firm $j$ is defined as $N_{j}^{*}=W_{j} / w$ where

$$
w=\frac{\sum_{j} W_{j}}{\sum_{j} N_{j}}
$$

is the average wage paid per worker in the market. Although correcting for wage differences across firms in this manner does reduced the spread and skew of the implied productivity distribution somewhat, both distributions have high variance and skew and are essentially the same general shape.

Figure 1: Productivity Distributions

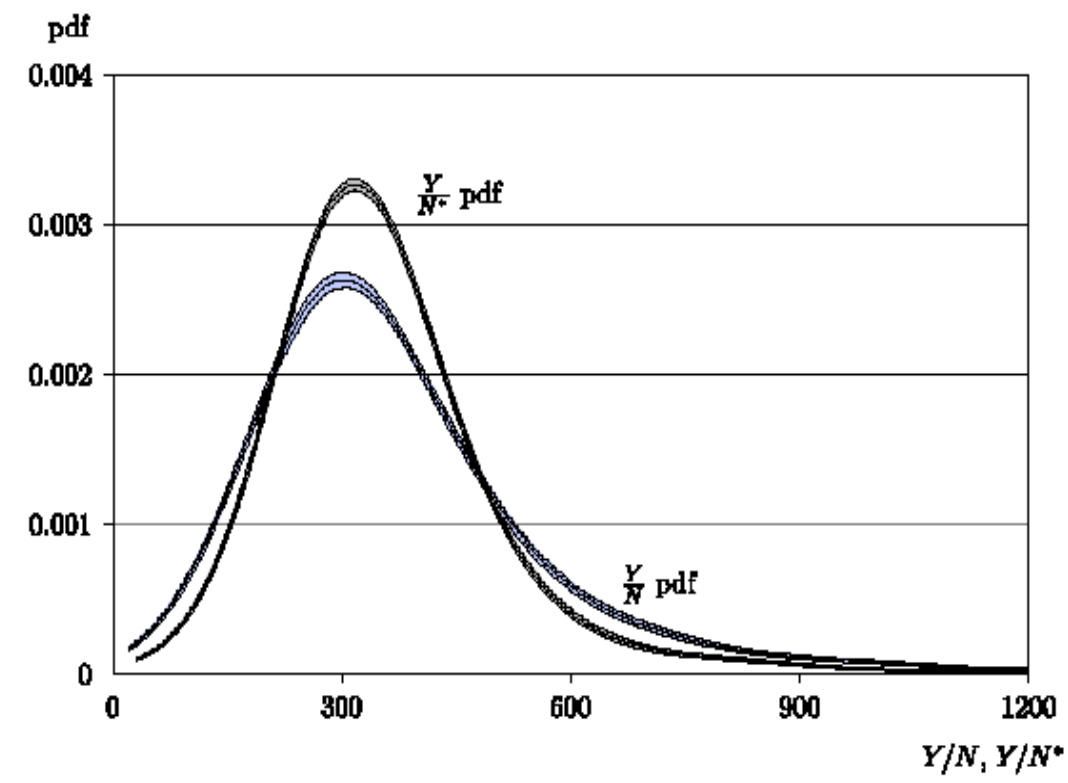

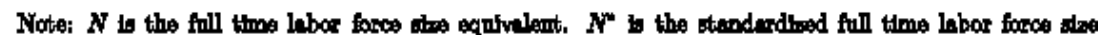
equlvilamt. The sheded areas representrt $90 \%$ confldenco bosmds

Figure 2:

Both distributions are consistent with those found in other data sets. For example, productivity distributions are significantly dispersed and skewed to the right. In the case of the adjusted measure of productivity, the $5^{\text {th }}$ 
percentile is roughly half the mode while the $95^{\text {th }}$ percentile is approximately twice as large are the mode. The range between the two represents a four fold difference in value added per worker across firms. These facts are similar to those reported by Bertelsman and Doms (2000) for the U.S.

There are many potential explanations for cross firm productivity differentials. A comparison of the two distributions represented in Figures 1 suggests that differences in the quality of labor inputs does not seem to be the essential one. The process of technology diffusion is a well documented. Total factor productivity differences across firms can be expected as a consequence of slow diffusion of new techniques. If technical improvements are either factor neutral or capital augmenting, then one would expect that more productive firms would acquire more labor and capital. The implied consequence would seem to be a positive relationship between labor force size and labor productivity. Interestingly, there is no correlation between the two in Danish data.

Table 1: Productivity - Size Correlations

\begin{tabular}{l|ccc}
\hline \hline & Employment (N) & Adjusted Employment $\left(\mathrm{N}^{*}\right)$ & Value Added (Y) \\
$\mathrm{Y} / \mathrm{N}$ & 0.0331 & 0.1397 & 0.3944 \\
$\mathrm{Y} / \mathrm{N}^{*}$ & 0.0114 & -0.0076 & 0.2618
\end{tabular}

The correlations between the two measures of labor productivity with the two employment measures and sales as reflected in value added are reported in Table 1. As documented in the table, the correlation between labor force size and productivity using either the raw employment measure or the adjusted one is zero. However, note the strong positive associate between value added and both measures of labor productivity. Non-parametric regressions of value added and employment on the two productivity measures are illustrated in Figure 2. The top and bottom curves in the figures represent a $90 \%$ confidence interval for the relationship. The positive relationships between value added and both measure of labor productivity are highly significant.

The theory developed in this paper is motivated by these observations. Specifically, it is a theory that postulates labor saving technical progress of a specific form. Hence, the apparent fact that more productive firms produce more with roughly the same labor input per unit of value added is consistent with the model. 

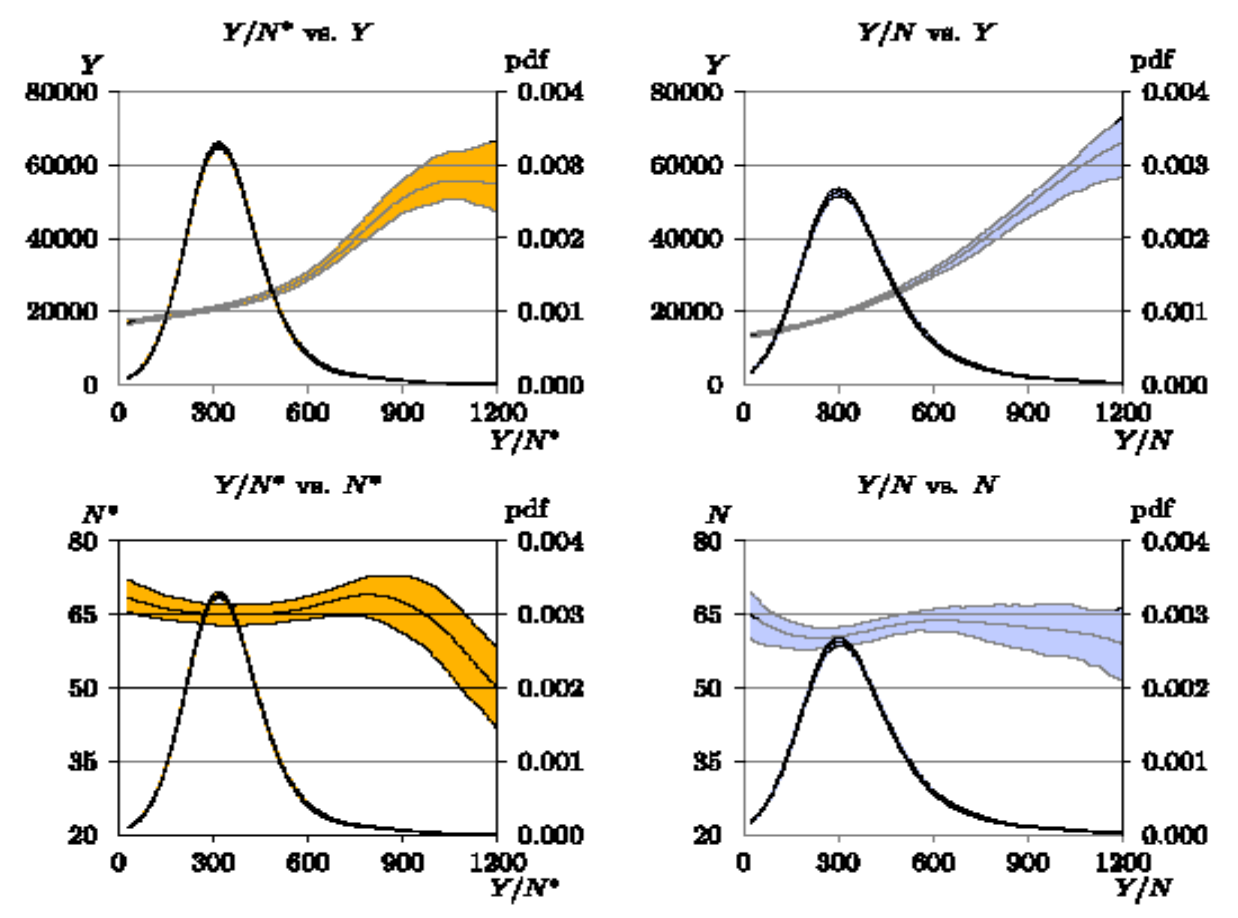

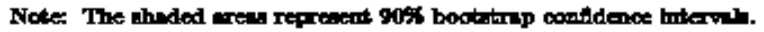

Figure 3:

\section{An Equilibrium Model of Creative Destruc- tion}

As is well known, firms come is an amazing range of shapes and sizes. This fact cannot be ignored in any analysis of the relationship between firm size and productivity. Furthermore, an adequate theory must account for entry, exit and firm evolution in order to explain the size distributions observed. Klette and Kortum (2004) construct a stochastic model of firm product innovation and growth that is consistent with stylized facts regarding the firm size evolution and distribution. The model also has the property that technical progress is labor saving. For these reasons, we pursue their approach in this paper.

Although Klette and Kortum allow for productive heterogeneity, firm 
productivity and growth are unrelated because costs and benefits of growth are both proportional to firm productivity in their model. Allowing for a positive relationship between firm growth and productivity is necessary for consistency with the relationships found in the Danish firm data studied in this paper.

\subsection{Preferences and Technology}

Intertemporal utility of the representative household at time $t$ is given by

$$
U_{t}=\int_{t}^{\infty} \ln C_{s} e^{-\rho(s-t)} d s
$$

where $\ln C_{t}$ denotes the instantaneous utility of the single consumption good at date $t$ and $\rho$ represents the pure rate of time discount. Each household is free to borrow or lend at interest rate $r_{t}$. Nominal household expenditure at date $t$ is $E_{t}=P_{t} C_{t}$. Optimal consumption expenditure must solve the differential equation $\dot{E} / E=r_{t}-r$. Following Grossman and Helpman (1991), we choose the numeraire so that $E_{t}=1$ for all $t$ without loss of generality, which implies $r_{t}=r=\rho$ for all $t$. Note that this choice of the numeraire also implies that price of the consumption good, $P_{t}$, falls over time at a rate equal to the rate of growth in consumption.

The quantity of the consumption produced is determined by the quantity and quality of the economy's intermediate inputs. Specifically, there is a unit continuum of inputs and consumption is determined by the production function

$$
\ln C_{t}=\int_{0}^{1} \ln \left(A_{t}(j) x_{t}(j)\right) d j=\ln A_{t}+\int_{0}^{1} \ln x_{t}(j) d j
$$

where $x_{t}(j)$ is the quantity of input $j \in[0,1]$ at time $t, A_{t}(j)$ is the productivity of input $j$ at time $t$, and $A_{t}$ represent aggregate productivity. The level of productivity of each input and aggregate productivity are determined by the number of technical improvements made in the past. Specifically,

$$
A_{t}(j)=\Pi_{i=1}^{J_{t}(j)} q_{i}(j) \text { and } \ln A_{t} \equiv \int_{0}^{1} \ln A_{t}(j) d j .
$$

where $J_{t}(j)$ is the number of innovations made in input $j$ up to date $t$ and $q_{i}(j)>1$ denotes the quantitative improvement (step size) in productivity 
attributable to the $i^{\text {th }}$ innovation in product $j$. Innovations arrive at rate $\delta$ which is endogenous but the same for all intermediate products.

The model is constructed so that a steady state growth path exists with the following properties: Consumption output grows at a constant rate while the quantities of intermediate products and the endogenous innovation frequency are stationary and identical across all intermediate goods. As a consequence of the law of large numbers, the assumption that the number of innovations to date is Poisson with arrival frequency $\delta$ for all intermediate goods implies

$$
\begin{aligned}
\ln C_{t} & =\ln A_{t}+\int_{0}^{1} \ln x(j) d j=\int_{0}^{1} \sum_{i=1}^{J_{t}(j)} \ln q_{i}(j) d j+\int_{0}^{1} \ln x(j) d j \\
& =E \ln (q) \delta t+\int_{0}^{1} \ln x(j) d j
\end{aligned}
$$

where $E J_{t}(j)=\delta t$ for all $j$ is the expected number of innovations per intermediate product and $E \ln (q) \equiv \int_{0}^{1} \frac{1}{J_{t}(j)} \sum_{i=1}^{J_{t}(j)} \ln q_{i}(j) d j$ is the expected quality step size. In other words, consumption grows at the rate of growth in productivity which is the product of the creative-destruction rate and the expected log of the size of an improvement in productivity induced by each new innovation.

\subsection{The Value of a Firm}

Each individual firm is the monopoly supplier of the products it created in the past that have survived to the present. The price charged for each is limited by the ability of suppliers of previous versions to provide a substitute. In Nash-Bertrand equilibrium, any innovator takes over the market for its good type by setting the price just below that at which consumers are indifferent between the higher quality product supplied by the innovator and an alternative supplied by the last provider. The price charged is the product of the relative quality and the previous producer's marginal cost of production. Given the symmetry of demands for the different good types and the assumption that future quality improvements are independent of the type of good, one can drop the good subscript without confusion. Given stationary of quantities along the equilibrium growth path, the time subscript can be dropped as well. 
Labor is the only factor in the production of intermediate inputs. Labor productivity is the same across all inputs and is set equal to unity. Hence, $p=q w$ is the price in terms of the numeraire of every intermediate good as well as the value of labor productivity where $w$, the wage, represents the marginal cost of production of the previous supplier and $q>1$ is the step up in quality of the innovation. As total expenditure is normalized at unity and there is a unit measure of product types, it follows that total revenue per product type is also unity given the specification of preferences and technology, i.e., $p x=1$. Hence, product output and employment are both equal to

$$
x=\frac{1}{p}=\frac{1}{w q} .
$$

and the gross profit associated with supplying the good is

$$
1>\pi=p x-w x=1-\frac{1}{q}>0 .
$$

The labor saving nature of improvements in intermediate input quality is implicit in the fact that labor demand is decreasing in $q$.

Following Klette and Kortum (2002), the discrete number of products supplied by a firm, denoted as $k$, is defined on the integers and its value evolves over time as a birth-death process reflecting product creation and destruction. In their interpretation, $k$ reflects the firm's past successes in the product innovation process as well as current firm size. New products are generated by R\&D investment. The firm's R\&D investment flow generates new product arrivals at frequency $\gamma k$. The total R\&D investment cost is $w c(\gamma) k$ where $c(\gamma) k$ represents the labor input required in the research and development process. The function $c(\gamma)$ is assumed to be strictly increasing and convex. According to the authors, the implied assumption that the total cost of $\mathrm{R} \& \mathrm{D}$ investment is linearly homogenous in the new product arrival rate and the number of existing product, "captures the idea that a firm's knowledge capital facilitates innovation." In any case, this cost structure is needed to obtain firm growth rates that are independent of size as typically observed in the data.

The market for any current product supplied by the firm is destroyed by the creation of a new version by some other firm, which occurs at the rate $\delta$. Below we refer to $\gamma$ as the firm's creation rate and to $\delta$ as the common de- 
struction rate faced by all firms. ${ }^{1}$ As product gross profit and product quality are one-to-one, the profits earned on each product reflects a firm's current labor productivity. The firm chooses the creation rate $\gamma$ to maximize the expected present value of its future net profit flow conditional on information that is relevant for predicting the quality of future innovations.

Firms differ with the respect to the quality of their products. Hence, each type is characterized by profitability, $\pi$, as defined in equation (7). The value of the firm of type $\pi$ that currently markets $k$ products is

$$
r V_{k}(\pi)=\max _{\gamma \geq 0}\left\{\begin{array}{c}
{[\pi-w c(\gamma)] k+\gamma k\left[E\left\{V_{k+1}(\pi)\right\}-V_{k}(\pi)\right]} \\
+\delta k\left[V_{k-1}(\pi)-V_{k}(\pi)\right]
\end{array}\right\} .
$$

The first term on the right side is current gross profit flow accruing to the firms product portfolio less current expenditure on R\&D. The second term is the expected capital gain associated with the arrival of a new product line. Finally, the last term represents the expected capital loss associated with the possibility that one among the existing product lines will be destroyed.

The unique solution to (8) is proportional to the number of product lines. Formally,

$$
V_{k}(\pi)=k \max _{\gamma \geq 0}\left\{\frac{\pi-w c(\gamma)}{r+\delta-\gamma}\right\}
$$

as one can verify by substitution. Consequently, any positive optimal choice of the product creation rate for a type $\pi$ firm must satisfy

$$
w c^{\prime}(\gamma(\pi))=V_{k+1}-V_{k}=\max _{\gamma \geq 0}\left\{\frac{\pi-w c(\gamma)}{r+\delta-\gamma}\right\}
$$

Hence, the second order condition, $c^{\prime \prime}(\gamma)>0$, and the fact that the marginal value of a product line is increasing in $\pi$ imply that the a firm's creation rate increases with profitability.

\subsection{Firm Entry and Labor Market Clearing}

The entry of a new firm requires an innovation. Suppose that there are a constant measure $m$ of identical potential entrants. The rate at which any one of them generates a new product is $\gamma_{0}$ and the total cost is $w c\left(\gamma_{0}\right)$ where the

\footnotetext{
${ }^{1}$ These are in fact the continuous time job creation and job destruction rates respectively as defined in Davis et al. (1996).
} 
cost function is the same as that faced by an incumbent. The firm's type is unknown ex ante but is realized immediately after entry. Since the expected return to innovation is $E_{\pi}\left\{V_{1}\right\}$ and the aggregate entry rate is $\eta=m \gamma_{0}$, the entry rate satisfies the following free entry condition

$$
w c^{\prime}\left(\frac{\eta}{m}\right)=\int_{\pi} V_{1}(\pi) \phi(\pi) d \pi=\int_{\pi} \max _{\gamma \geq 0}\left\{\frac{\pi-w c(\gamma)}{r+\delta-\gamma}\right\} \phi(\pi) d \pi
$$

where $\phi(\pi)$ is the density of entrant of type $\pi$ and the second equality follows from equation (10).

There is a fixed measure of available workers, denoted by $L$, seeking employment at any positive wage. In equilibrium, these are allocated across production and R\&D activities, those performed by both incumbent firms and potential entrants. Since the number of workers employed for production purposes per product of quality $q$ is $x=1 / w q=(1-\pi) / w$ from equations (6) and (7), the total number demanded for production activity by firms of type $\pi$ with $k$ products is $L_{x}(k, \pi)=k(1-\pi) / w>0$. The number of R\&D workers employed by incumbent firms of type $\pi$ with $k$ products is $L_{R}(k, \pi)=k c(\gamma(\pi))$. Because each potential entrant innovates at frequency $\eta / m$, the aggregate number of worker engaged by all $m$ in $R \& D$ is $L_{E}=$

$m c(\eta / m)$. Hence, the equilibrium wage satisfies the labor market clearing condition

$$
\begin{aligned}
L & =\int_{\pi} \sum_{k=1}^{\infty}\left[L_{x}(k, \pi)+L_{R}(k, \pi)\right] M_{k}(\pi) d \pi+L_{E} \\
& =\int_{\pi}\left(\frac{1-\pi}{w}+c(\gamma(\pi))\right) \sum_{k=1}^{\infty} k M_{k}(\pi) d \pi+m c(\eta / m) .
\end{aligned}
$$

\subsection{The Steady State Distribution of Firm Size}

Once a firm enters, its size as reflected in the number of product lines supplied evolves as a birth-death process. As the set of firms with $k$ products at a point in time must either have had $k$ products already and neither lost nor gained another, have had $k-1$ and innovated, or have had $k+1$ and lost one to destruction over any sufficiently short time period, the equality of the flows into and out of the set of firms of type $\pi$ with $k>1$ products requires

$$
\gamma(\pi)(k-1) M_{k-1}(\pi)+\delta(k+1) M_{k+1}(\pi)=(\gamma+\delta) k M_{k}(\pi)
$$


for every $\pi$ where $M_{k}(\pi)$ is the steady state mass of firms of type $\pi$ that supply $k$ products. Because an incumbent dies when its last product is destroyed by assumption but entrants flow into the set of firms with a single product at rate $\eta$,

$$
\phi(\pi) \eta+2 \delta M_{2}(\pi)=(\gamma(\pi)+\delta) M_{1}(\pi)
$$

where $\phi(\pi)$ is the fraction of the new entrants that realize profit $\pi$. Births must equal deaths in steady state and only firms with one product are subject to death risk. Therefore, $\phi(\pi) \eta=\delta M_{1}(\pi)$ and

$$
M_{k}(\pi)=\frac{k-1}{k} \gamma(\pi) M_{k-1}=\frac{\eta \phi(\pi)}{\delta k}\left(\frac{\gamma(\pi)}{\delta}\right)^{k-1}
$$

by induction.

The size distribution of firms conditional on type can be derived using equation (13). Specifically, the total firm mass of type $\pi$ is

$$
\begin{aligned}
M(\pi) & =\sum_{k=1}^{\infty} M_{k}(\pi)=\frac{\phi(\pi) \eta}{\delta} \sum_{k=1}^{\infty} \frac{1}{k}\left(\frac{\gamma(\pi)}{\delta}\right)^{k-1} \\
& =\frac{\eta}{\delta} \ln \left(\frac{\delta}{\delta-\gamma(\pi)}\right) \frac{\delta \phi(\pi)}{\gamma(\pi)}
\end{aligned}
$$

where convergence requires that the aggregate rate of creative destruction exceed the creation rate of every incumbent type, i.e., $\delta>\gamma(\pi) \forall \pi$. Hence, the fraction of type $\pi$ firm with $k$ product is

$$
\frac{M_{k}(\pi)}{M(\pi)}=\frac{\frac{1}{k}\left(\frac{\gamma(\pi)}{\delta}\right)^{k}}{\ln \left(\frac{\delta}{\delta-\gamma(\pi)}\right)} .
$$

This is the logarithmic distribution with parameter $\gamma(\pi) / \delta .{ }^{2}$ Consistent with the observations on firm size distributions, that implied by the model is highly skewed to the right.

By equation (15), the mean of the firm size distribution conditional on product profitability is

$$
E\{k \mid \pi\}=\sum_{k=1}^{\infty} \frac{k M_{k}(\pi)}{M(\pi)}=\frac{\frac{\gamma(\pi)}{\delta-\gamma(\pi)}}{\ln \left(\frac{\delta}{\delta-\gamma(\pi)}\right)},
$$

\footnotetext{
${ }^{2}$ This result is in Klette and Kortum (1992). We include the derivation here simply for completeness.
} 
As the product creation rate increases with profitability, expected size does also. Formally, because $(1+a) \ln (1+a)>a>0$ for all positive values of $a$, the expected number of product produced increasing in firm profitability is

$$
\frac{\partial E\{k \mid \pi\}}{\partial \pi}=\left(\frac{(1+a(\pi)) \ln (1+a(\pi))-a(\pi)}{(1+a(\pi)) \ln ^{2}(1+a(\pi))}\right) \frac{\delta \gamma^{\prime}(\pi)}{(\delta-\gamma(\pi))^{2}}>0
$$

where $a(\pi)=\frac{\gamma(\pi)}{\delta-\gamma(\pi)}$.

Equation (17) implies that more profitable firms supply more products. However, because innovation is labor saving in the sense that production employment per product supplied decreases with profitability, total expected employment, $n E k$ where $n=(1-\pi) / w+c(\gamma(\pi))$, need not increase with $\pi$ in general and decreases with $\pi$ if innovation is not related to profitability. Hence, the hypothesis that firms with the ability to create products of better quality grow faster is consistent with dispersion in labor productivity and the correlations between value added, labor force size, and labor productivity observed in Danish data reported above.

Finally, the rate of creative-destruction is the sum of the entry rate and the aggregate creation rates of all the incumbents given that the total mass

of products is fixed. Because the new product arrival rate of a firm of type $\pi$ with $k$ products is $\gamma(\pi) k$ and the measure of such firms is $M_{k}(\pi)$,

$$
\delta=\eta+\int_{\pi} \gamma(\pi) \sum_{k=1}^{\infty} k M_{k}(\pi) d \pi .
$$

\subsection{Equilibrium}

Definition A steady state market equilibrium is a triple composed of a labor market clearing wage $w$, entry rate $\eta$, and creative destruction rate $\delta$ together with an optimal creation rate $\gamma(\pi)$ and a steady state size distribution $M_{k}(\pi)$ for each type that satisfy equations (11), (12), (10), (13), and (18) provided that $\gamma(\pi)<\delta$, for every $\pi$ in the support of the entry distribution.

Proposition If the cost of innovation, $c(\gamma)$, is strictly convex and $c^{\prime}(0)=$ $c(0)=0$, then a steady state market equilibrium with positive entry exists. In the case of a single firm type, there is only one. 
Proof. See Lentz and Mortensen (2004). ${ }^{3}$

\section{Estimation}

If product quality is a permanent firm characteristic, then differences in firm profitability are associated with differences in the product creation rates chosen by firms. Specifically, more profitable firms grow faster, are more likely to survive in the future, and supply a larger number of products on average. Hence, a positive cross firm correlation between current gross profit per product and sales volume should exist. Furthermore, worker reallocation from slow growing firms that supply products of lesser quality to more profitable fast growing firms will be an important sources of aggregate productivity growth. On the other hand, if product quality is iid across innovations and firms, all firms grow at the same rate even though persistent differences in profitability exist as a consequence of different realizations of product quality histories.

In this section, we demonstrate that firm specific differences in profitability are required to explain Danish interfirm relationships between value added, employment, and wages paid. In the process of fitting the model to the data, we also obtain estimates of the investment cost of innovation function that all firms face as well as the sampling distribution of firm productivity at entry.

\subsection{Danish Firm Data}

If more productive firm's grow faster in the sense that $\gamma^{\prime}(\pi)>0$, then (17) implies that more productive firms also supply more products and sell more on average. However, because production employment per product decreases with productivity, total expected employment, $n E k$ where $n=(1-\pi) / w+$ $c(\gamma(\pi))$, need not increase with $\pi$ in general and decreases with $\pi$ when growth is independent of a firm's past product quality realizations. These implications of the theory can be tested directly.

The model is estimated on an unbalanced panel of 4,872 firms drawn from the Danish firm panel described in Section 2. The panel is constructed by selecting all existing firms in 1992 with more than 20 workers and following

\footnotetext{
${ }^{3}$ Although the cost of entry is linear in the paper cited while the cost is convex here, the principal arguments hold in this case.
} 
Table 1: Data Moments (std dev in parenthesis)

\begin{tabular}{|c|c|c|c|c|c|}
\hline & 1992 & 1997 & & 1992 & 1997 \\
\hline Survivors & $\begin{array}{r}4,872.00 \\
-\end{array}$ & $\begin{array}{r}3,628.00 \\
(32.14)\end{array}$ & $E\left[\frac{Y}{N^{*}}\right]$ & $\begin{array}{r}364.36 \\
(2.74)\end{array}$ & $\begin{array}{r}410.61 \\
(4.85)\end{array}$ \\
\hline$E[Y]$ & $\begin{array}{r}26,277.26 \\
(747.32)\end{array}$ & $\begin{array}{r}31,860.85 \\
(1,031.62)\end{array}$ & $S t d\left[\frac{Y}{N^{*}}\right]$ & $\begin{array}{r}193.40 \\
(18.13)\end{array}$ & $\begin{array}{r}290.11 \\
(40.86)\end{array}$ \\
\hline $\operatorname{Med}[Y]$ & $\begin{array}{r}13,471.00 \\
(211.68)\end{array}$ & $\begin{array}{r}16,432.10 \\
(330.11)\end{array}$ & $\operatorname{Cor}\left[\frac{Y}{N^{*}}, \frac{Y_{+1}}{N_{+1}^{*}}\right]$ & $\begin{array}{r}0.48 \\
(0.09)\end{array}$ & $\begin{array}{r}0.55 \\
(0.09)\end{array}$ \\
\hline$E[W]$ & $\begin{array}{r}13,294.48 \\
(457.68)\end{array}$ & $\begin{array}{r}15,705.09 \\
(609.63)\end{array}$ & $\operatorname{Cor}\left[\frac{Y}{N^{*}}, \Delta \frac{Y}{N^{*}}\right]$ & $\begin{array}{r}-0.23 \\
(0.10)\end{array}$ & $\begin{array}{r}-0.19 \\
(0.06)\end{array}$ \\
\hline $\operatorname{Med}[W]$ & $\begin{array}{r}7,229.70 \\
(92.75)\end{array}$ & $\begin{array}{l}8,670.28 \\
(155.84)\end{array}$ & $\operatorname{Cor}[Y, W]$ & $\begin{array}{r}0.85 \\
(0.04)\end{array}$ & $\begin{array}{r}0.86 \\
(0.05)\end{array}$ \\
\hline$S t d[Y]$ & $\begin{array}{r}52,798.52 \\
(5,679.64)\end{array}$ & $\begin{array}{r}64,129.07 \\
(7,757.99)\end{array}$ & $\operatorname{Cor}\left[\frac{Y}{N^{*}}, Y\right]$ & $\begin{array}{r}0.20 \\
(0.04)\end{array}$ & $\begin{array}{r}0.14 \\
(0.04)\end{array}$ \\
\hline$S t d[W]$ & $\begin{array}{r}30,616.94 \\
(6,778.09)\end{array}$ & $\begin{array}{r}35,560.60 \\
(8,157.15)\end{array}$ & $\operatorname{Cor}\left[\frac{Y}{N^{*}}, N^{*}\right]$ & $\begin{array}{r}-0.02 \\
(0.01)\end{array}$ & $\begin{array}{r}-0.03 \\
(0.01)\end{array}$ \\
\hline
\end{tabular}

them through time, while all firms that enter the sample in the subsequent years are excluded. In the estimation, the observed 1992 cross-section will be interpreted to reflect steady state whereas the following years generally do not reflect steady state since survival probabilities vary across firm types. Specifically, the observed cross-sections from 1993 to 1997 will have an increasing over-representation of high creation rate firm types relative to steady state due to selection. The sampling choice is partly driven by data limitations but is also useful in identifying dynamic features of the model. Table 1 presents a number of data moments with standard deviations in parenthesis. The standard deviations are obtained by bootstrapping. Nominal amounts are in 1,000 DKK.

\subsection{Model Estimator}

An observation in the panel is given by $\psi_{i t}=\left(Y_{i t}, W_{i t}, N_{i t}^{*}\right)$, where $Y_{i t}$ is real value added, $W_{i t}$ the real wage sum, and $N_{i t}^{*}$ quality adjusted labor force 
size of firm $i$ in year $t$. Let $\psi_{i}$ be defined by, $\psi_{i}=\left(\psi_{i 1, \ldots}, \psi_{i T}\right)$ and finally, $\psi=\left(\psi_{1}, \ldots, \psi_{I}\right)$

The model is estimated by use of a simulated minimum distance estimator as described in for example Gourieroux, Monfort, and Renault (1993), Hall and Rust (2003), and Alvarez, Browning, and Ejrnæs (2001). First, define a vector of data moments, $\Gamma(\psi)$. The vector consists of all the moments in Table 1 except the number of survivors in 1992. Thus, $\Gamma(\psi)$ consists of 27 moments. ${ }^{4}$

Second, $\psi^{s}(\omega)$ is simulated from the model for a given set of model parameters $\omega$. The model simulation is initialized by assuming that the economy is in steady state in the first year and consequently that firm observations are distributed according to the $\omega$-implied steady state distribution. Alternatively, one can initialize the simulation according to the observed data in the first year, $\left(\psi_{11}, \ldots, \psi_{1 I}\right)$. The assumption that the economy is initially in steady state provides additional identification in that $\left(\psi_{11}, \ldots, \psi_{1 I}\right)$ can be compared to the model-implied steady state distribution $\left(\psi_{11}^{s}(\omega), \ldots, \psi_{1 I}^{s}(\omega)\right)$. The simulated moments are then given by,

$$
\Gamma^{s}(\omega)=\frac{1}{S} \sum_{s=1}^{S} \Gamma\left(\psi^{s}(\omega)\right),
$$

where $S$ is the number of simulation repetitions.

The estimator is then the choice of parameters that minimizes the weighted distance between the data moments and the simulated moments,

$$
\hat{\omega}=\arg \min _{\omega \in \Omega}\left(\Gamma^{s}(\omega)-\Gamma(\psi)\right)^{\prime} A^{-1}\left(\Gamma^{s}(\omega)-\Gamma(\psi)\right),
$$

where $A$ is some positive definite matrix. If $A$ is the identity matrix, $\hat{\omega}$ is the equally weighted minimum distance estimator (EWMD). If $A$ is the covariance matrix of the data moments $\Gamma(\psi), \hat{\omega}$ is the optimal minimum distance estimator (OMD). The OMD estimator is asymptotically more efficient than the EWMD estimator. However, Altonji and Segal (1996) show that the estimate of $A$ as the second moment matrix of $\Gamma(\cdot)$ may suffer from serious small sample bias. Horowitz (1998) suggest an alternative estimator of $A$ based on bootstrap methods. The estimation in this paper adopts Horowitz's estimator of the covariance matrix $A$.

\footnotetext{
${ }^{4}$ The term "moment" is used loosely here. One can alternatively describe $\Gamma$ as containing a set of auxiliary parameters as in Gourieroux et al. (1993) where the proxy model that generates the auxiliary parameters is then quite simplistic.
} 


\subsection{Model Simulation}

To fit the data, the model simulation produces time paths for value added $(Y)$, the wage sum $(W)$, and labor force size $(N)$ for $I$ firms. The estimation introduces a stochastic demand realization for each of a firm's products, $\tilde{Z}$. Thus, the demand for product $j$ is given by $x_{j}=\tilde{Z} / p_{j}$. The random variable, $\tilde{Z}$, is iid across products and time and is assumed to follow a log-normal distribution,

$$
\tilde{Z}=\exp \left(\tilde{\xi} \sigma_{z}+\mu_{z}\right) \text { where } \tilde{\xi} \sim N(0,1) .
$$

Denote the expected value of $\widetilde{Z}$ as $E\{\tilde{Z}\}=Z$.

To properly capture the labor share in the data, a capital cost $\kappa \equiv K / Z$ is added to the model where $K$ is the capital associated with the production of a given product and $\kappa$ is the capital cost relative to average product expenditure. This modifies the pricing of the intermediary goods. Now, providing an intermediary good at price $p$ yields expected operational profits, $Z(1-w / p-\kappa)$. Thus, the price of intermediary good $j$ is, $p=$ $q w /(1-\kappa)$ since consumers are exactly indifferent between buying from the quality leader at this price and the from the immediate follower at price $p=w /(1-\kappa)$, which is as low as the follower is willing to go. The inclusion of a non-labor cost then modifies the definition of production profits, $\pi$, as defined in (7). The more general definition that allows for non-labor cost is given by,

$$
\pi=(1-\kappa)\left(1-q^{-1}\right),
$$

which is identical to (7) if $\kappa=0$.

The quality of each new innovation (and thereby the profit associated with it) is a stochastic realization drawn from a distribution which is contingent on the firm's type. Specifically, the profit of any particular innovation is assumed to satisfy

$$
\widetilde{\pi}=(1-\kappa)\left(1-\widetilde{q}^{-1}\right), \text { where } \widetilde{q}=1+\exp \left(\xi \sigma_{\widetilde{\pi}}+\mu_{\widetilde{\pi}}(\pi)\right) \text { and } \xi \sim N(0,1) \text {. }
$$

where the mean $E\{\tilde{\pi} \mid \pi\}=\pi$ represents the firm's profitability type, the determinant of its creation rate. Each firm's type is itself a random variable realized after entry. We assume that the steady state distribution profit distribution, denoted as $p(\pi)$, is characterized by

$$
\pi=(1-\kappa)\left(1-q^{-1}\right), \text { where } q=1+\exp \left(z \sigma_{\pi}+\mu_{\pi}\right) \text { and } z \sim N(0,1)
$$


where in both $(21)$ and $(22) N(0,1)$ represents the standard normal distribution. For future reference,

$$
p(\pi) \equiv \frac{M(\pi)}{\int_{\pi} M(\pi) d \pi}
$$

where $M(\pi)$, the steady state mass of firms of type, is given by equation (14).

Denote by $\Pi^{k}=\left(\pi_{1}, \ldots, \pi_{k}\right)$ the quality realizations of a firm's $k$ products. The value added of a type $\pi$ firm with $k$ products characterized by $\Pi^{k}$ is given by,

$$
Y_{k}\left(\Pi^{k}, \pi\right)=\sum_{i=1}^{k} Z_{i},
$$

where each product demand realization $Z_{i}$ is drawn according to (19). The wage bill is given by,

$$
W_{k}\left(\Pi^{k}, \pi\right)=\sum_{i=1}^{k} Z_{i}\left(1-\kappa-\pi_{i}\right)+k Z w \tilde{c}(\gamma(\pi)),
$$

where $\widehat{c}(\gamma)=c(\gamma) / Z$.

Lentz and Mortensen (2004) analyze the firm's creation rate choice in the general case where product quality is a stochastic process. Because the value of the next product is linear in profit and the profit realizations across products are iid for each firm, the optimal choice of creation rate for a firm of type $\pi$ solves,

$$
\gamma(\pi)=\arg \min _{\gamma} \frac{E\{\tilde{\pi}\}-w \widehat{c}(\gamma)}{r+\delta-\gamma}=\arg \min _{\gamma} \frac{\pi-w \widehat{c}(\gamma)}{r+\delta-\gamma}
$$

as in the deterministic case sketch above. Specify the cost function as $\widehat{c}(\gamma)=$ $c_{0} \gamma^{1+c_{1}}$. Then, the first order condition for the optimal creation rate choice is,

$$
w\left(1+c_{1}\right) c_{0} \gamma^{c_{1}}(r+\delta-\gamma)=\pi-w c_{0} \gamma^{1+c_{1}} .
$$

Equations (24) and (25) provide the foundation for the model simulation. It then remains to simulate product paths for all firms. The simulation is initialized by the assumption of steady state. By (15), the steady state 
product size distribution conditional on survival is given by,

$$
\operatorname{Pr}\left(k^{*}=k \mid \pi\right)=\frac{M_{k}(\pi)}{M(\pi)}=\frac{\frac{1}{k}\left(\frac{\gamma(\pi)}{\delta}\right)^{k}}{\ln \left(\frac{\delta}{\delta-\gamma(\pi)}\right)} .
$$

First, a firm's type, $\pi$, is determined according to (22). Then, the initial product size of a firm $\left(k_{1}\right)$ is determined following $(28)$.

With a given initial product size, simulation of the subsequent time path requires knowledge of the transition probability function $\operatorname{Pr}\left(k_{2}=k \mid k_{1}, \pi\right)$. Denote by $p_{\pi, n}(t)$ the probability of a type $\pi$ firm having product size $n$ at time $t$. As shown in Klette and Kortum (2004), $p_{\pi, n}(t)$ evolves according to the ordinary differential equation system,

$$
\begin{aligned}
& \dot{p}_{\pi, n}(t)=(n-1) \gamma(\pi) p_{\pi, n-1}(t)+(n+1) \delta p_{\pi, n+1}(t)-(\delta+\gamma(\pi)) p_{\pi, n}(t), \forall n \geq 1 \\
& \dot{p}_{\pi, 0}(t)=\delta p_{\pi, 1}(t) .
\end{aligned}
$$

Hence, with the initial condition,

$$
p_{\pi, n}(0)=\left\{\begin{array}{l}
1 \text { if } n=k_{1} \\
0 \text { otherwise }
\end{array}\right.
$$

one can determine $\operatorname{Pr}\left(k_{2}=k \mid k_{1}, \pi\right)$ by solving the differential equation system in (29) for $p_{\pi, k}(1)$. Solving for $p_{\pi, k}(1)$ involves setting an upper reflective barrier to bound the differential equation system. It has been set sufficiently high so as to avoid biasing the transition probabilities. Based on the transition probabilities $\operatorname{Pr}\left(k_{t+1}=k \mid k_{t}, \pi\right)$ one can then iteratively simulate product size paths for each firm. The procedure correctly captures the evolution of $k_{t}$ but it does not identify the exact evolution of $\Pi^{k_{t}}$. The evolution of $\Pi^{k_{t}}$ is assumed to follow the net change in products. ${ }^{5}$

Finally, the simulation allows for an exogenous growth factor in both value added and the wage bill, denoted as $\widehat{g}$, that is independent of the endogenous quality improvements produced by incumbents and entrants.

\footnotetext{
${ }^{5}$ Suppose firm $i$ is simulated to loose 1 product in a given year. In this case, $\Pi^{k_{i t}}$ is updated by randomly eliminating one element from it. This assumes that the net loss of 1 product took place by the gross destruction of 1 product and zero gross creation. This is the most likely event by which the firm loses 1 product. However, the net loss could also come about by the gross destruction of 2 products and gross creation of 1 product during the year. In this case, $\Pi^{k_{i t}}$ should be updated by randomly eliminating 2 elements and adding 1 . There are in principle an infinite number of ways that the firm can loose 1 product over the year. The estimation consequently over-estimates the persistency of $\Pi^{k_{i t}}$. The bias will go to zero as the period length is reduced, though.
} 
Table 2: Model Parameter Estimates

\begin{tabular}{lrlr} 
& Point Estimates & & Inferred Estimates \\
\hline$c_{0}$ & 422.829 & $\eta$ & 0.036 \\
$c_{1}$ & 4.537 & $m$ & 0.619 \\
$\kappa$ & 0.369 & $M$ & 0.568 \\
$Z$ & $13,856.662$ & $L$ & 41.021 \\
$\delta$ & 0.095 & $\bar{\gamma}$ & 0.059 \\
$\sigma_{z}^{2}$ & 0.900 & $w$ & 181.77 \\
$\sigma_{\widetilde{\pi}}^{2}$ & 2.011 & & \\
$\mu_{\pi}$ & -2.075 & & \\
$\sigma_{\pi}^{2}$ & 2.076 & & \\
$\widehat{g}$ & 0.014 & & \\
\hline
\end{tabular}

\subsection{Identification}

The set of model parameters to be identified $(\omega)$ is given by,

$$
\omega=\left\{c_{0}, c_{1}, \delta, \kappa, Z, \sigma_{z}^{2}, \sigma_{\widetilde{\pi}}^{2}, \sigma_{\pi}^{2}, \mu_{\pi}, \widehat{g}\right\} \in \Omega,
$$

where $\Omega$ is the feasible set of model parameters choices. The interest rate will be set at $r=.05$. The wage $w$ is immediately identified as the average worker wage in the sample $w=181.77$. Experimentation with non-parametric identification of the firm type distribution has been performed with a distribution with 4 support points. Because the results showed little sensitivity in the remaining model parameters to this alternative specification, we report only those parameters obtained given the assumed parametric distribution of types.

\subsection{Estimation Results}

The model parameter estimates are given in table 2 .

Table 3 produces a comparison of the data moments and the simulated moments associated with the model parameter estimates.

The estimated model does well in fitting the labor productivity distribution and the correlations between productivity and firm size. These relationships are also shown in Figure 4. The model over-estimates the persistence in labor productivity and the mean reversion over time in labor productivity. The model seems to face a trade-off on this dimension. It can reduce 
Table 3: Data Moments (top row) and Simulated Moments (bottom row)

\begin{tabular}{|c|c|c|c|c|c|}
\hline & 1992 & 1997 & & 1992 & 1997 \\
\hline \multirow{2}{*}{ Survivors } & $4,872.00$ & $3,628.00$ & \multirow{2}{*}{$E\left[\frac{Y}{N^{*}}\right]$} & 364.36 & 410.61 \\
\hline & $4,872.00$ & $3,631.11$ & & 368.46 & 400.28 \\
\hline \multirow{2}{*}{$E[Y]$} & $26,277.26$ & $31,860.85$ & \multirow{2}{*}{$S t d\left[\frac{Y}{N^{*}}\right]$} & 193.40 & 290.11 \\
\hline & $24,352.57$ & $29,424.92$ & & 213.71 & 232.99 \\
\hline \multirow{2}{*}{ Med $[Y]$} & $13,471.00$ & $16,432.10$ & \multirow{2}{*}{$\operatorname{Cor}\left[\frac{Y}{N^{*}}, \frac{Y_{+1}}{N_{+1}^{*}}\right]$} & 0.48 & 0.55 \\
\hline & $13,462.73$ & $16,488.22$ & & 0.69 & 0.69 \\
\hline \multirow{2}{*}{$E[W]$} & $13,294.48$ & $15,705.09$ & \multirow{2}{*}{$\operatorname{Cor}\left[\frac{Y}{N^{*}}, \Delta \frac{Y}{N^{*}}\right]$} & -0.23 & -0.19 \\
\hline & $12,216.06$ & $14,485.07$ & & -0.37 & -0.36 \\
\hline \multirow{2}{*}{$\operatorname{Med}[W]$} & $7,229.70$ & $8,670.28$ & \multirow{2}{*}{$\operatorname{Cor}[Y, W]$} & 0.85 & 0.86 \\
\hline & $7,163.16$ & $8,675.06$ & & 0.90 & 0.89 \\
\hline \multirow{2}{*}{$S t d[Y]$} & $52,798.52$ & $64,129.07$ & \multirow{2}{*}{$\operatorname{Cor}\left[\frac{Y}{N^{*}}, Y\right]$} & 0.20 & 0.14 \\
\hline & $35,572.63$ & $42,219.59$ & & 0.19 & 0.20 \\
\hline \multirow{2}{*}{$S t d[W]$} & $30,616.94$ & $35,560.60$ & \multirow{2}{*}{$\operatorname{Cor}\left[\frac{Y}{N^{*}}, N^{*}\right]$} & -0.02 & -0.03 \\
\hline & $15,192.27$ & $17,519.39$ & & -0.02 & -0.02 \\
\hline
\end{tabular}

the labor productivity persistence but in doing so, the mean reversion is increased even further. The estimated model does not quite replicate the thickness of the very right tail of the firm size distribution and consequently it under-estimates the variance in value added and the wage bill. Notice that the model successfully captures the right shift of the $Y$ and $W$ distributions from 1992 to 1997. This is partly a result of a positive exogenous growth estimate. But more importantly the estimated right shift is caused by a positive correlation between value added and survival probability that stems from firm type heterogeneity. Large firms in 1992 are on average also higher creation rate types and they face less net destruction over time than the small firms. If all firms faced the same net destruction rate, the $Y$ and $W$ distributions should shift to the left over time.

Given the steady state equilibrium definition, one can infer the overall entry rate, $\eta$, and the measure of potential entrant, $m .{ }^{6}$ The implied values of these parameters are also reported in Table 2. The average incumbent

\footnotetext{
${ }^{6}$ The formulas used to make the calculations are presened in the appendix.
} 
Figure 4: Firm Productivity and Size, 1992 (Data and Simulation).

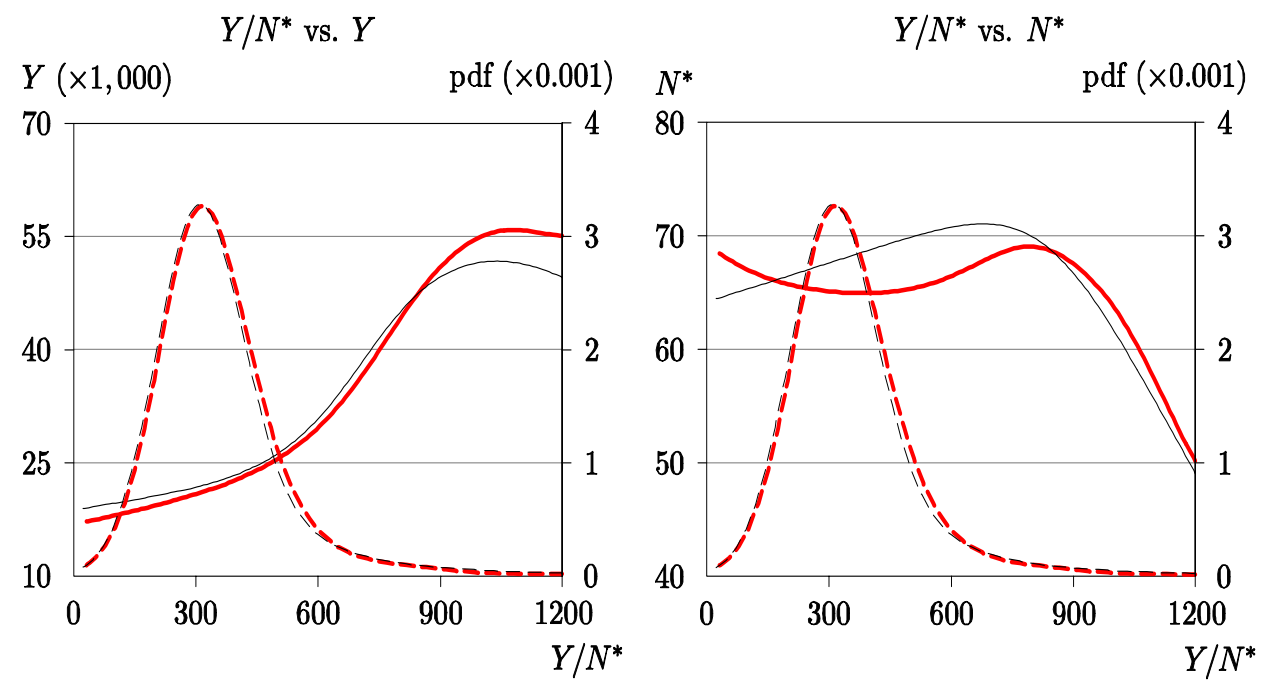

Note: Observed relationships drawn in bold pen and estimated relationships drawn in thin pen.

creation rate, $\bar{\gamma}$, is simply the difference between the entry rate and the destruction rate. It is seen that the estimates imply that roughly one third of all innovation comes from entrants. Given the estimated steady state distribution of firms, $p(\pi)$, and the other parameters of the model, one can also infer the ex ante type distribution, $\phi(\pi)$. The two distributions are shown in Figure 5 along with the incumbent creation rate choice conditional on firm type. It is clear from the figure that the higher quality type firms choose higher creation rates and consequently grow faster. Therefore, those with higher products will make up a large relative fraction of firms in steady state relative to the distribution of types at entry. The consequences of this fact for aggregate growth are explored more fully in the next section.

The estimation is performed given the assumption that the true firm population of interest coincides with the size censoring in the data. That is, the estimation does not correct for size censoring bias. While this is obviously a strong assumption, it does on the other hand seem reasonable to argue that the large number of single person firms in the economy are qualitatively different from the firms in this analysis and not just firms with less products. 
Figure 5: Creation Rate Choice and Firm Type Distributions.
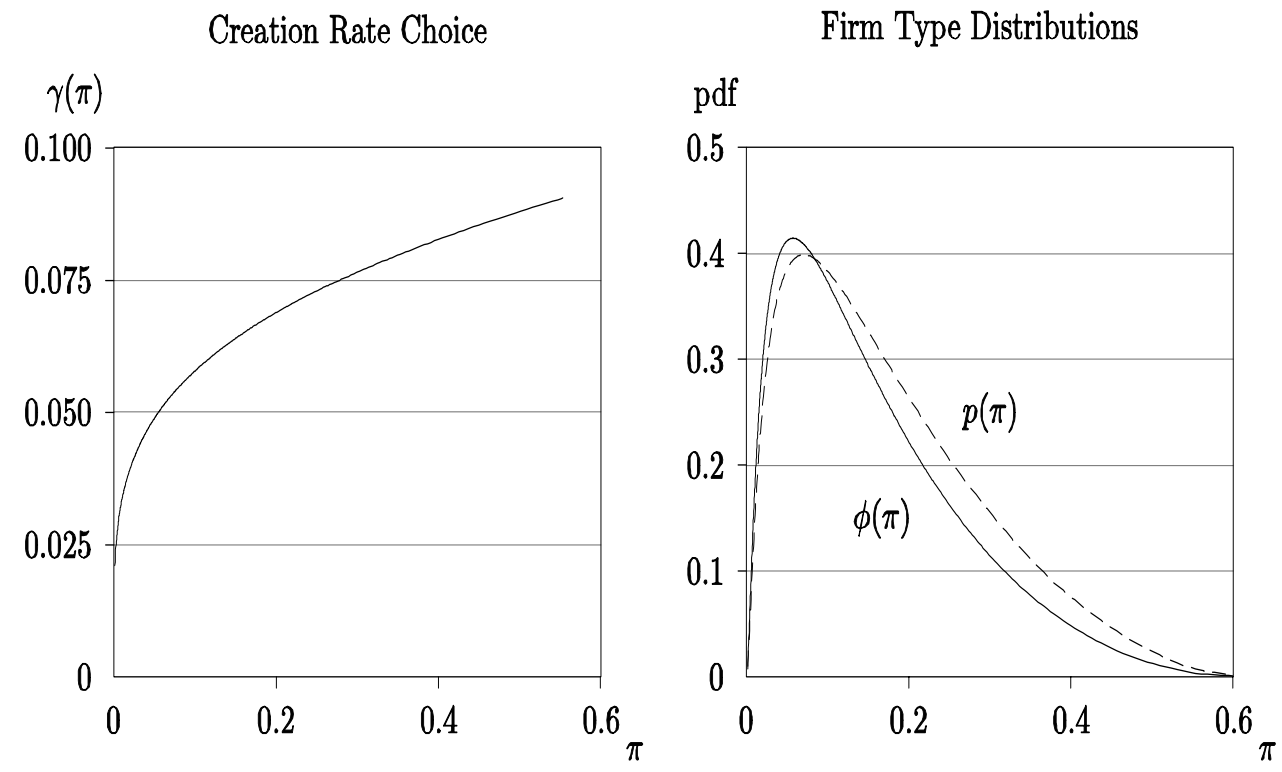

The estimation can be disaggregated to a single digit industry level. Future versions of the paper will include such estimations. Data moments by industry have turned out to be qualitatively similar to the data moments for the entire economy. Consequently, it is not likely that the fundamental estimation results will be sensitive to industry disaggregation.

As is generally the case, the estimation is sensitive to the choice of data moments. Currently, the estimation has focused on capturing the crosssection moments primarily. Future work will include a larger set of dynamic moments. It should be noted though that since the estimation is performed on cross-section moments not just in 1992 but also in 1997 and because of the specific sampling procedure in the data, the estimation does implicitly address dynamic features of the model as well. The trends in the moments over time are interpreted as a result of systematic selection bias due to creation rate heterogeneity across types.

At a theoretical level, the model satisfies Gibrat's law; for identical type firms, the creation rate is size independent. However, due to selection, larger firms will tend to over-represent higher creation rate types and this effect should tend to imply a positive relationship between size and growth rate. 
The mean reversion in demand and to a smaller extend in supply shocks introduces an opposite effect, though; the group of small firms today will tend to over-represent firms with adverse demand shocks. Chances are that the demand realizations in the next period will reverse the fortunes of these firms and they will experience relatively large growth rates. Large firms have many products and experience less overall demand variance. The latter effect turns out to dominate in the estimated model. The estimated correlation between firm size and growth rate is roughly -0.2 . The corresponding correlation in the data is -0.1 .

\section{Reallocation and Growth}

If more profitable firms grow faster, then workers move from less to more profitable surviving firms as well as from exiting to entering firms. This selection effect can be demonstrated by noting that more profitable firms are over represented (relative to their fraction at entry) among those that produce more than one product and that this "selection bias" increases with the number of products produced. Namely, by equation (13), the difference between the relative fraction of a given firm type in the surviving population with $k$ products and relative the fraction in its entry cohort,

$$
\frac{M_{k}\left(\pi^{\prime}\right)}{M_{k}(\pi)}-\frac{\phi\left(\pi^{\prime}\right)}{\phi(\pi)}=\frac{\phi\left(\pi^{\prime}\right)}{\phi(\pi)}\left[\left(\frac{\gamma\left(\pi^{\prime}\right)}{\gamma(\pi)}\right)^{k-1}-1\right],
$$

is positive and increasing in $k$ when $\pi^{\prime}>\pi$.

From equation (5), the equilibrium rate of growth in consumption is

$$
\begin{aligned}
\dot{\bar{C}} & =g=\delta E \ln q \\
& =\delta\left(\int_{\pi} \ln (q(\pi)) \frac{\eta \phi(\pi) d \pi}{\delta}+\int_{\pi} \ln (q(\pi)) \frac{\gamma(\pi) \sum_{k=1}^{\infty} k M_{k}(\pi) d \pi}{\delta}\right) \\
& =\eta \int_{\pi} \ln q(\pi) \phi(\pi) d \pi+\int_{\pi} \gamma(\pi) \ln q(\pi) \sum_{k=1}^{\infty} k M_{k}(\pi) d \pi
\end{aligned}
$$

where $q(\pi)=1 /(1-\pi)$ is the quality of the products of a type $\pi$ firm and $\delta$ is the aggregate rate of creative destruction as defined in equation (18). The 
decomposition of the rate of productivity growth,

$$
\begin{aligned}
g= & \eta \int_{\pi} \ln q(\pi) \phi(\pi) d \pi+\int_{\pi} \gamma(\pi) \ln q(\pi) \phi(\pi) d \pi \\
& +\int_{\pi} \gamma(\pi) \ln q(\pi)\left[\frac{\eta}{\delta-\gamma(\pi)}-1\right] \phi(\pi) d \pi
\end{aligned}
$$

where $\frac{\eta \phi(\pi)}{\delta-\gamma(\pi)}=\sum_{k=1}^{\infty} k M_{k}(\pi)$ from equation (13), highlights the role of worker reallocation from exiting to entering firms as well as from less to more productive firms as sources of productivity growth. The first term is the net effect of entry and exist on productivity growth. The second term is the contribution of continuing firms to growth given no firm size selection. Finally, the last term represents the contribution of firm size selection that induces by worker reallocation among surviving firms that continually takes place as a consequence of the creative destruction process.

Since the total measure of products is unity $\left(\int_{\pi} \sum_{k=1}^{\infty} k M_{k}(\pi) d \pi=1\right)$ and $\phi(\pi) d \pi$ is the fraction of entrants of type $\pi,\left(\int_{\pi} \phi(\pi) d \pi=1\right)$, it follows that

$$
0=\int_{\pi}\left[\sum_{k=1}^{\infty} k M_{k}(\pi)-\phi(\pi)\right] d \pi=\int_{\pi}\left(\frac{\eta}{\delta-\gamma(\pi)}-1\right) \phi(\pi) d \pi
$$

Hence, the fact that $\gamma(\pi)$ is strictly increasing in $\pi$ implies that the contribution to growth of the reallocation of workers among continuing firms, the last term in (32), is positive. Equivalently, it is positive because $\gamma(\pi) \ln q(\pi)$ is strictly increasing in $\pi$ and the steady state distribution of types stochastically dominates the distribution of types at entry as a consequence of the firm size selection process.

Given the parameter estimates reported in the previous section, the implied aggregate growth rate and its components are

$$
\begin{aligned}
\text { Growth Rate: } & g=3.39 \text { percent per year. } \\
\text { Net Entry: } & \eta \int_{\pi} \ln q(\pi) \phi(\pi) d \pi=0.66 . \\
\text { Continuing : } & \int_{\pi} \gamma(\pi) \ln q(\pi) \phi(\pi) d \pi=1.25 . \\
\text { Reallocation: } & \int_{\pi} \gamma(\pi) \ln q(\pi)\left[\sum_{k=1}^{\infty} k M_{k}(\pi)-\phi(\pi)\right] d \pi=1.47 .
\end{aligned}
$$


These calculations raise several interesting issues. First, they imply an over all growth rate in productivity somewhat larger than the standard measures. This fact provides indirect support for arguments that the measurement methodologies currently in use fail to fully separate quality improvements from price increases. ${ }^{7}$ In addition, the estimates imply that worker reallocation from both exiting to entering firms and among surviving firms account for $19.5 \%$ and $45.5 \%$ respectively of the aggregate rate of growth. These numbers suggest a very important role to both forms of reallocation.

\section{The Planner's Problem}

The market equilibrium solution need not be socially optimal for at least three reasons. First, the providers of intermediate inputs have monopoly power and use it to set the price above the marginal cost of production. Second, by replacing an existing product, an innovation has a negative external effect on existing firms. Finally, because each quality improvement builds on those of previous products, innovation has a positive "spill over" effect on future productivity. The net deviation of the equilibrium growth rate from that which is socially optimal is unclear. One of the contributions of a quantitative equilibrium model is its ability to reflect light on which effect dominates.

Firm types are characterized by the profitability of their products, $\pi$. The density of type $\pi$ firms at entry is $\phi(\pi)$. The mass of firm's of type $\pi$ that produce $k$ products, denoted $M_{k}(\pi)$, is a state variable as well as the aggregate productivity parameter, $A$. The problem is to choose times paths for the production rate, $\left\{x_{t}(\pi)\right\}$, and the rate of new product creation, $\left\{\gamma_{t}(\pi)\right\}$, for each firm type, the aggregate rate of firm entry $\eta_{t}$, and the rate of creative destruction $\delta_{t}$ to maximize the present discounted utility of the representative household's consumption subject to the creation-destruction identity, the labor resource constraint, and the laws of motion for the state variables. Specifically, the planner's strategy maximizes

$$
\int_{0}^{\infty} \ln C_{t} e^{-r t} d t=\int_{0}^{\infty}\left[\ln A_{t}+\sum_{\pi} \ln x_{t}(\pi) \sum_{k=1}^{\infty} k M_{k s}(\pi) e^{-r t}\right] d t
$$

\footnotetext{
${ }^{7}$ In the U.S., this argument is fully articulated in Boskin et al. (1996).
} 
subject to the constraints that product creation is equal to destruction,

$$
\delta=\eta+\int_{\pi} \gamma(\pi) \sum_{k=1}^{\infty} k M_{k}(\pi) d \pi
$$

that employment does not exceed the available supply,

$$
\int_{\pi}[x(\pi)+c(\gamma(\pi))] \sum_{k=1}^{\infty} k M_{k}(\pi) d \pi+m c\left(\frac{\eta}{m}\right) \leq L
$$

and the laws of motion of aggregate productivity

$$
\frac{d \ln A}{d t}=g=\eta \int_{\pi} \ln \pi(q) \phi(\pi) d \pi+\int_{\pi} \gamma(\pi) \ln q(\pi) \sum_{k=1}^{\infty} k M_{k}(\pi) d \pi,
$$

and the distribution of products across types and size of firm characterized by

$\dot{M}_{k}(\pi)=\gamma(\pi)(k-1) M_{k-1}(\pi)+\delta(k+1) M_{k+1}(\pi)-(\gamma(\pi)+\delta) k M_{k}(\pi), k>1$

and

$$
\dot{M}_{1}(\pi)=\phi(\pi) \eta+2 \delta M_{2}(\pi)-(\gamma(q)+\delta) M_{1}(\pi)
$$

for every value of $\pi$ in the support of the distribution at entry. The last two equations reflect the fact that only firms with $k-1$ products that create another and firms with $k+1$ products that loose one flow into the set of firms with $k$ products in any instant while those with $k$ products that either acquire another or loose one exit from the set and that new firms enter with a single product.

It is convenient to let $\mu_{k}(\pi)=k M_{k}(\pi)$ represent the fraction of all firms that are of both type $\pi$ and supply $k$ products. From the equations above, it follows that

$$
\begin{aligned}
& \dot{\mu}_{k}(\pi)=\left[\gamma(\pi) \mu_{k-1}(\pi)+\delta \mu_{k+1}(\pi)-(\gamma(\pi)+\delta) \mu_{k}(\pi)\right] k \\
& \dot{\mu}_{1}(\pi)=\phi(\pi) \eta+\delta \mu_{2}(\pi)-(\gamma(\pi)+\delta) \mu_{1}(\pi) .
\end{aligned}
$$


The present value Hamiltonian for the problem can be written as

$$
\begin{aligned}
H= & \ln A+\int_{\pi} \ln x_{t}(\pi) \sum_{k=1}^{\infty} \mu_{k}(\pi) d \pi \\
& +\omega\left(L-\int_{\pi}[x(\pi)+c(\gamma(\pi))] \sum_{k=1}^{\infty} \mu_{k}(\pi) d \pi-m c\left(\frac{\eta}{m}\right)\right) \\
& +\theta\left(\delta-\eta-\int_{\pi} \gamma(\pi) \sum_{k=1}^{\infty} \mu_{k}(\pi) d \pi\right) \\
& +\lambda\left(\eta \int_{\pi} \ln q(v) \phi(\pi) d \pi+\int_{\pi} \gamma(\pi) \ln q(\pi) \sum_{k=1}^{\infty} \mu_{k}(\pi) d \pi\right) \\
& +\int_{\pi} \sum_{k=2}^{\infty} k \nu_{k}(\pi)\left[\gamma(\pi) \mu_{k-1}(\pi) d \pi+\delta \mu_{k+1}(\pi)-(\gamma(\pi)+\delta) \mu_{k}(\pi)\right] d \pi \\
& +\int_{\pi}\left[\nu_{1}(\pi) \phi(\pi) \eta+\delta \mu_{2}(\pi)-(\gamma(\pi)+\delta) \mu_{1}(\pi)\right] d \pi
\end{aligned}
$$

where $\omega$ and $\theta$ are multipliers associated respectively with the labor supply constraint and the definition of the rate of creative destruction while $\lambda$ is the shadow price of the state variable $\ln A$ and $v_{k}(\pi)$ is the shadow price associated with $\mu_{k}(\pi)$.

A solution with positive entry $(\eta>0)$ requires

$$
\begin{gathered}
\frac{\partial H}{\partial x(\pi)}=\left(\frac{1}{x(\pi)}-\omega\right) \sum_{k=1}^{\infty} \mu_{k}(\pi)=0 \forall \pi \\
\frac{\partial H}{\partial \gamma(\pi)}=\left(\begin{array}{c}
{\left[\lambda \ln q(\pi)-\theta-\omega c^{\prime}(\gamma(\pi))\right] \sum_{k=1}^{\infty} \mu_{k}(\pi)} \\
+\sum_{k=1}^{\infty}\left[\nu_{k+1}(\pi)(k+1)-v_{k}(\pi) k\right] \mu_{k}(\pi)
\end{array}\right)=0 \forall \pi \\
\frac{\partial H}{\partial \eta}=\lambda \sum_{\pi} \ln q(\pi) \phi(\pi)-\theta-\frac{\omega}{h}+\sum_{\pi} \nu_{1}(\pi) \phi(\pi)=0 \\
\frac{\partial H}{\partial \delta}=\theta+\sum_{\pi}\left[\sum_{k=2}^{\infty} k \nu_{k}(\pi)\left[\left(\mu_{k+1}(\pi)-\mu_{k}(\pi)\right]+\nu_{1}(\pi)\left(\mu_{2}(\pi)-\mu_{1}(\pi)\right)\right]\right. \\
=\theta-\sum_{\pi} \sum_{k=1}^{\infty}\left[k v_{k}(\pi)-(k-1) \nu_{k-1}(\pi)\right] \mu_{k}(\pi)=0
\end{gathered}
$$


and the co-state (Euler) equations are

$$
\begin{aligned}
\frac{\partial H}{\partial \ln A}= & 1=r \lambda-\dot{\lambda} \\
\frac{\partial H}{\partial \mu_{k}(\pi)}= & \ln x(\pi)-\omega[x(\pi)+c(\gamma(\pi))]-\theta \gamma(\pi)+\lambda \gamma(\pi) \ln q(\pi) \\
& +\gamma(\pi)\left[(k+1) \nu_{k+1}(\pi)-k v_{k}(\pi)\right]-\delta\left[k v_{k}(\pi)-(k-1) \nu_{k-1}(\pi)\right] \\
= & r v_{k}(\pi)-\dot{v}_{k}(\pi) \forall \pi .
\end{aligned}
$$

By substitution it follows that any solution has the property that $v(q)=$ $v_{k}(q)$ for all $k$. Namely, $v(q)$, the shadow value of any intermediate good created by a firm of type $\pi$, does not depend on the number of product supplied. Hence, one can rewrite the necessary conditions for a solution as

$$
\begin{aligned}
1= & \omega x(\pi), \forall \pi . \\
\omega c^{\prime}(\gamma(\pi))= & v(\pi)-\theta+\lambda \ln q(\pi), \forall \pi . \\
\omega c^{\prime}\left(\frac{\eta}{m}\right)= & \int_{\pi}[v(\pi)-\theta+\lambda \ln q(\pi)] \phi(\pi) d \pi \\
\theta= & \int_{\pi} v(\pi) \sum_{k=1}^{\infty} \mu_{k}(\pi) d \pi . \\
1= & r \lambda-\dot{\lambda} . \\
r v(\pi)-\dot{v}(\pi)= & \ln x(\pi)-\omega[x(\pi)+c(\gamma(\pi))]-\theta \gamma(\pi) \\
& +\lambda \gamma(\pi) \ln q(\pi)+\gamma(\pi) v(\pi)-\delta v(\pi), \forall \pi .
\end{aligned}
$$

As efficiency requires that the marginal utility of each good should equal its marginal cost of production, the first equation implies that the amount produced of each product should be equal given our specification of the utility and production functions and the assumption that all require the same labor input to produce. Equilibrium production violates this condition. Indeed, because $x(\pi)=1 / w q(\pi)$ in equilibrium, higher quality intermediate inputs are under produced. The second conditions requires that the marginal cost of investing in a new product equal the expected shadow value a new product after appropriate account is taken of spill overs and externalities. The negative externality implicit in the innovation process is captured by the shadow price of the creative-destruction identity, $\theta$, while the positive spill over associated with the fact that each new product contributes to the productivity of the next is captured by the shadow value of its contribution 
to the aggregate productivity parameter, the product $\lambda \ln q(\pi)$. The third equation requires that the marginal cost of an innovation by an entrant must equal the expected shadow price of its product. The fourth reflects the fact that the shadow price of product destruction is equal the expected value of the existing set of products. The last two Euler equations define the shadow prices as the expected present value of the future returns to an unit addition to log of the level of productivity and to the stock of products of type $\pi$ respectively.

In steady state

$$
\begin{aligned}
\lambda & =\frac{1}{r} \\
v(\pi) & =\frac{\ln x(\pi)-1+\omega \gamma(\pi) c^{\prime}(\gamma(\pi))-\omega c(\gamma(\pi))}{r+\delta}, \\
\sum_{k=1}^{\infty} \mu_{k}(\pi) & =\frac{\eta \phi(\pi)}{\delta-\gamma(\pi)} .
\end{aligned}
$$

Because the total number of intermediate products is of unit measure,

$$
\sum_{\pi} \sum_{k=1}^{\infty} \mu_{k}(\pi)=1,
$$

the steady state solution to the planner's problem solves

$$
\begin{aligned}
\omega c^{\prime}(\gamma(\pi)) & =\frac{1}{r} \ln q(\pi)+v(\pi)-\sum_{z} v(z) \frac{\eta \phi(z)}{\delta-\gamma(z)} \\
\text { where } v(\pi) & =\frac{\ln (1 / \omega)-1+\omega \gamma(\pi) c^{\prime}(\gamma(\pi))-\omega c(\gamma(\pi))}{r+\delta}, \forall \pi \\
c^{\prime}\left(\frac{\eta}{m}\right) & =\int_{\pi} c^{\prime}(\gamma(\pi)) \phi(\pi) d \pi . \\
1 & =\eta \int_{\pi} \frac{\phi(\pi) d \pi}{\delta-\gamma(\pi)} . \\
L & =\frac{1}{\omega}+\int_{\pi} c(\gamma(\pi)) \frac{\eta \phi(\pi) d \pi}{\delta-\gamma(\pi)}+m c\left(\frac{\eta}{m}\right) .
\end{aligned}
$$

It is impossible to characterize the relationship between the optimal growth rate and that obtained in equilibrium in general qualitative terms. However, given the estimated model and the equilibrium conditions, one can compute 
the components of the optimal growth rate and compare them the equilibrium values reported in equation (33). The results are

$$
\begin{aligned}
\text { Growth Rate: } & g=5.71 \text { percent per year } \\
\text { Net Entry: } & \eta \int_{\pi} \ln q(\pi) \phi(\pi) d \pi=0.68 \\
\text { Continuing: } & \int_{\pi} \gamma(\pi) \ln q(\pi) \phi(\pi) d \pi=1.28 \\
\text { Reallocation: } & \int_{\pi} \gamma(\pi) \ln q(\pi)\left[\sum_{k=1}^{\infty} k M_{k}(\pi)-\phi(\pi)\right] d \pi=3.75 .
\end{aligned}
$$

A comparison of these results with those of (33) suggest that the equilibrium growth rate is substantially less than that which is socially optimal. Indeed the difference is $5.71-3.39=2.32$ percent per year. Although the optimal entry rate and the creative-destruction rates are larger $(\eta=0.0391$ and $\delta=0.1124$ respectively) than their corresponding equilibrium values, the larger role of reallocation in the solution to the social planner's problem accounts for virtually all the difference in the two growth rates. Figure 6, which illustrates both the equilibrium and the socially optimal creation rate functions, provides an visual explanation for the difference. Namely, the optimal creation rate function is greater than and more steeply sloped than the equilibrium. By implication, more profitable firm types should be growing faster. If they were to do so, then firms that developed higher quality products would account for a larger fraction of the steady state distribution of firms and, consequently, would contribute more to aggregate growth.

\section{Concluding Remarks}

Large and persistent differences in firm productivity and firm size exist. Evidence suggests that the reallocation of workers across firms and establishments is an important source of aggregate economic growth. In earlier paper, we explore a variant of the equilibrium Schumpeterian model of firm size evolution developed by Klette and Kortum (2002) that provided insights into these and other empirical regularities. In our version of the model, firms that can develop more profitable intermediate products of higher quality grow larger at the expense of less profitable firms though a process of creative destruction. The worker reallocation from less to more profitable 
Figure 6: The Equilibrium $(\gamma(\pi))$ and Optimal $(\gamma o p t(\pi))$ Creation Rate Functions

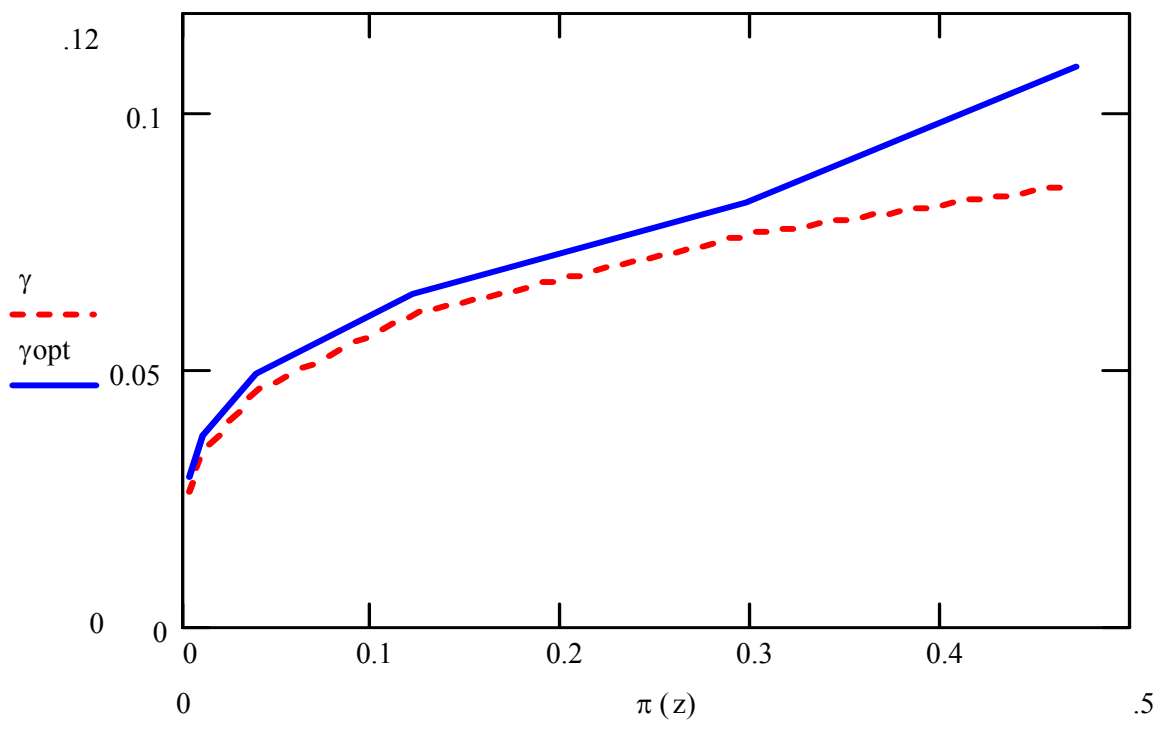

firms induced by the process contributes to aggregate productivity growth. Furthermore, the model is consistent with the observation that there is no correlation between employment size and labor productivity and a positive correlation between value added and labor productivity observed in Danish firm data.

In this paper, we take the model to the data. Namely, we fit its structure to Danish firm panel data for the 1992-1997 time period. We find that the parameter estimates are sensible and that the model provides a reasonable fit to many of the moments of the joint distribution of size as measured by value added and employment. The model also explains the evolution of size distribution of firms in the panel over the observation period. Finally, the quantitative model has interesting aggregate implications for the growth process. First, the implied rate of productivity growth, 3.39\% per year, is larger than estimates based on standard accounting methods. We suggest that this fact may support the claim that inflation rates are over stated because product quality improvement is not fully taken into account. Second, the quantitative model implies that the optimal rate of growth, that which a 
social planner would achieve, is substantially higher, 5.71\%. The difference is almost entirely explained by the fact that the social planner would require that firm able to make better product invest more in R\&D than then they do in the estimated equilibrium. Indeed, as a consequence the reallocation from less to more profitable continuing firms accounts for $65.6 \%$ of the socially optimal growth rate but only $43.5 \%$ of the equilibrium growth rate.

\section{Appendix}

In this section, we present the algorithm used to compute the values of model parameters implied by the estimates and the equilibrium and optimal growth rates, all reported in the text. To do so, one must account for the two parameters not explicitly used in the initial presentation of the model, the average demand per product, $Z$, which was normalized to unity in the model, and the cost of capital per product line, denoted $\kappa Z$. Hence, profit per product line can be represented as $\pi Z$ for a firm of type $\pi$ where

$$
\pi=(1-\kappa)\left(1-q^{-1}\right)
$$

is now profit express as a fraction of value average sales.

Since the parametric form of the steady state distribution of firms over profit, denoted $p(\pi)$ in the text, is specified in the model estimated, one needs to derive its relationship to the initial density of entering firms over profit, $\phi(\pi)$, by inverting the steady state relationship implied by the model. Specifically,

$$
p(\pi)=M(\pi) / M
$$

where $M(\pi)$ is the steady state mass of firms of type $\pi$ and $M=\int_{\pi} M(\pi) d \pi$ is the total mass of firms. Since

$$
M(\pi)=\sum_{k=1}^{\infty} M_{k}(\pi)=\ln \left(\frac{\delta}{\delta-\gamma(\pi)}\right) \frac{\eta \phi(\pi)}{\gamma(\pi)}
$$

from equation (13), it follows that

$$
\eta \phi(\pi)=\frac{\gamma(\pi) M(\pi)}{\ln \left(\frac{\delta}{\delta-\gamma(\pi)}\right)}=\frac{\gamma(\pi) p(\pi) M}{\ln \left(\frac{\delta}{\delta-\gamma(\pi)}\right)},
$$


At this stage, the aggregate entry rate $\eta$ and the total mass of firms $M$ have yet to be separately identified. But by $\int_{\pi} \phi(\pi) d \pi=1$, it follows that,

$$
\eta=\eta \int_{\pi} \phi(\pi) d \pi=M \int_{\pi} \frac{\gamma(\pi) p(\pi)}{\ln \left(\frac{\delta}{\delta-\gamma(\pi)}\right)} d \pi .
$$

Consequently, the profit density at entry is

$$
\phi(\pi)=\frac{\frac{\gamma(\pi) p(\pi)}{\ln \left(\frac{\delta}{\delta-\gamma(\pi)}\right)}}{\int_{x} \frac{\gamma(x) p(x)}{\ln \left(\frac{\delta}{\delta-\gamma(x)}\right)} d x} .
$$

Equation (15) and the assumption that the measure of products is unity, the steady state measure of continuing firms in the market solves

$$
\begin{aligned}
1 & =\int_{\pi} \sum_{k=1}^{\infty} k M_{k}(\pi) d \pi=\int_{\pi} M(\pi) \sum_{k=1}^{\infty} \frac{k M_{k}(\pi)}{M(\pi)} d \pi \\
& =\int_{\pi} \frac{\gamma(\pi) M(\pi)}{(\delta-\gamma(\pi)) \ln \left(\frac{\delta}{\delta-\gamma(\pi)}\right)} d \pi=M \int_{\pi} \frac{\gamma(\pi) p(\pi)}{(\delta-\gamma(\pi)) \ln \left(\frac{\delta}{\delta-\gamma(\pi)}\right)} d \pi .
\end{aligned}
$$

Hence,

$$
\eta=\frac{\int_{\pi} \frac{\gamma(\pi) p(\pi)}{\ln \left(\frac{\delta}{\delta-\gamma(\pi)}\right)} d \pi}{\int_{\pi} \frac{\gamma(\pi) p(\pi)}{(\delta-\gamma(\pi)) \ln \left(\frac{\delta}{\delta-\gamma(\pi)}\right)} d \pi} .
$$

from by equations (39) and (41).

To solve the planner's problem, one also needs the size of the aggregate labor force, $L$, and the measure of potential entrants, $m$. Because one can show that the limit price charged by the current supplier of each product solves $p(1-\kappa)=w q$ when a capital cost exists, the demand for production workers is $Z x(\pi)=1 / p=Z(1-\kappa) / w q=Z(1-\kappa-\pi) / w$ from (38). Hence, equations (12) and (13) imply

$$
L=Z\left[\int_{\pi}\left(\frac{1-\kappa-\pi}{w}+\widehat{c}(\gamma(\pi))\right) \frac{\eta \phi(\pi) d \pi}{\delta-\gamma(\pi)}+m \widehat{c}(\eta / m)\right]
$$

where, as specified in the text, $\widehat{c}(x)=c_{0} x^{1+c_{1}}$. Finally, one can obtain the value of $m$ by using the fact that the marginal cost of entry must equal the 
expected marginal cost of innovation by incumbents. Specifically, equations (11) and (10) imply require that $m$ solves

$$
\widehat{c}^{\prime}\left(\frac{\eta}{m}\right)=\int_{\pi} \widehat{c}^{\prime}(\gamma(\pi)) \phi(\pi) d \pi
$$

Finally, the parametric specification of heterogeneity in product quality is

$$
q(z)=1+e^{\mu_{\pi}+\sigma_{\pi} z}
$$

where $z$ is the standard normal random variable. Hence, one can use the fact that $f(z) d z=p(\pi(z)) d \pi(z)$, where $f(z)$ is the standard normal pdf and $\pi(z)=(1-\kappa)\left(1-q(z)^{-1}\right)$ by (38), to compute all the necessary integrals in the equations above and those that define the components of the growth rate found in the text.

\section{References}

[1] Altonji, J. G., and L. M. Segal (1996): "Small-Sample Bias in GMM Estimation of Covariance Structures," Journal of Business and Economic Statistics, 14, 353\{366.

[2] Alvarez, J., M. Browning, and M. Ejrn (2001): "Modelling Income Processes with Lots of Heterogeneity," Working Paper.

[3] Baily, M., C. Hulton, and D. Campbell (1992). "Productivity Dynamics in Manufacturing Plants," Brookings Papers on Economic Activity, Microeconomics, 187-249.

[4] Bertelsman, E., and M. Doms (2000) "Understanding Productivity: Lessons from Longitudinal Microdata," Journal of Economics Literature, 38: 569-594.

[5] Boskin, Michael J., Dulberger, Eller R., Gordon, Robert J., Griliches, Zvi, and Jorgenson,Dale (1996). Toward a More Accurate Measure of the Cost of Living, Final Report tothe Senate Finance Committee from the Advisory Commission to Study theConsumer Price Index. Washington: Senate Finance Committee, December 4. 
[6] Christensen, B.J., R. Lentz, D.T. Mortensen, G.R. Neumann, and A. Werwatz (2002) "On the Job Search and the Wage Distribution." Forthcoming in the Journal of Labor Economics.

[7] Davis, S.J., and J. Haltiwanger (1991). "Wage Dispersion within and between Manufacturing Plants," Brookings Papers of Economic Activity: Microeconomics, 115-180.

[8] Davis, S.J., and J. Haltiwanger (1999). "Gross Job Flows," in Ashenfelter and Card (eds.), Handbook of Labor Economics vol 3. Elsevier Science.

[9] Dunne, T., L. Foster, J. Haltiwanger, and K.R. Troske (2002) "Wage and Productivity Dispersion in U.S. Manufacturing: The Role of Computer Investment," forthcoming in the Journal of Labor Economics.

[10] Fallick, B.C., and C.A. Fleischman (2001) "The Importance of Employer-to-Employer Flows in the U.S. Labor Market, Finance and Economics Discussion Paper 2001-18, Federal Reserve Board, Washing D.C.

[11] Foster, L., J. Haltiwanger and C.J. Krizan (2001), "Aggregate Productivity Growth: Lessons from Microeconomic Evidence" in C.R. Hulten, E.R. Dean and M.J. Harper, eds., New Developments in Productivity Analysis. Chicago: University of Chicago Press.

[12] Frederiksen, A., and N. Westergaard-Nielsen (2002) "Where Did They Go." Aarhus School of Business working paper, Aarhus, DK.

[13] Gourieroux, C., A. Monfort, and E. Renault (1993). "Indirect Inference," Journal of Applied Econometrics, 8(0), S85-S118.

[14] Grossman, G. and E. Helpman (1991). Innovation and Growth in the Global Economy. Cambridge, Ma: MIT Press.

[15] Hall, G., and J. Rust (2003). "Simulated Minimum Distance Estimation of a Model of Optimal Commodity Price Speculation with Endogenously Sampled Prices," Working Paper.

[16] Horowitz, J. L. (1998). "Bootstrap Methods for Covariance Structures," Journal of Human Resources, 33, 39\{61. 
[17] Klette, J., and S. Kortum (2002). "Innovating Firms and Aggregate Innovation," NBER Working Paper 8819.

[18] Lentz, R., and D.T. Mortensen (2003). "Productivity Differences and Firm Size: Is a Firm More Than the Sum of Its Parts?", Northwestern Working Paper.

[19] Mortensen, D.T. (2003). Wage Dispersion: Why are similar workers paid differently. Cambridge, Ma: MIT Press.

[20] Stewart (2002) "Recent Trends in Job Stability and Job Security." U.S. BLS Working Paper 356. 